\title{
ON JAMES TYPE CONSTANTS AND THE NORMAL STRUCTURE IN BANACH SPACES
}

\begin{abstract}
ZHAN-FEI ZUO
Abstract. In this paper, we establish the lower bounds for the weakly convergent sequence coefficient $W C S(X)$ of a Banach space $X$, in terms of the James type constant $J_{X, t}(\tau)$, the coefficient of weak orthogonality $\mu(X)$ and Domínguez-Benavides coefficient $R(1, X)$. By mean of these bounds, we identify some geometrical properties implying normal structure. Meanwhile, the James type constant $J_{X, t}(\tau)$, the coefficient of weak orthogonality $\mu(X)$ and DomínguezBenavides coefficient $R(1, X)$ for the Bynum space $l_{2, \infty}$ are computed to show that our estimates are sharp.
\end{abstract}

Mathematics subject classification (2010): 46B20, 46B25.

Keywords and phrases: James type constant, weakly convergent sequence coefficient, normal structure.

\section{REFERENCES}

[1] J. Alonso And E. Llorens-Fuster, Geometric mean and triangles inscribed in a semicircle in Banach spaces, J. Math. Anal. Appl., 340, 2 (2008), 1271-1283.

[2] A. Ayerbe-Toledano, T. Domínguez Benavides and G. López-Acedo (Eds), Measures of Noncompactness in Metric Fixed Point Theory, Oper. Theory Adv. Appl., 99, Birkhäuser, Basel, 1997.

[3] W. B YNum, Normal structure coefficients for Banach spaces, Pacific J. Math., 86, 2 (1980), 427-436.

[4] E. CASINI P. PAPINI AND S. SAEJUng, Some estimates for the weakly convergent sequence coefficient in Banach spaces, J. Math. Anal. Appl., 346, 1 (2008), 177-182.

[5] S. DhOMPONGSA AND A. KAEWKHAO, An inequality concerning the James constant and the weakly convergent sequence coefficient, J. Nonlinear Convex Anal., 8, 2 (2007), 325-333.

[6] T. Domínguez BenAVIDES, A geometrical coefficient implying the fixed point property and stability results, Houston J. Math., 22, 4 (1996), 835-849.

[7] J. GAO AND K. LAU, On two classes of Banach spaces with uniform normal structure, Studia Math., 99, 1 (1991), 41-56.

[8] J. GAO, A Pythagorean approach in Banach spaces, J. Inequal. Appl., 2006, 1 (2006), 1-11.

[9] A. Jiménez-Melado, E. Llorens-Fuster and S. Saejung, The von Neumann-Jordan constant, weak orthogonality and normal structure in Banach spaces, Proc. Amer. Math. Soc., 134, 2 (2006), 355-364.

[10] M. Kato, L. Maligranda And Y. Takahashi, On James and Jordan-von Neumann constants and normal structure coefficient of Banach spaces, Studia Math.,144, 3 (2001), 275-295.

[11] W. KIRK, A fixed point theorem for mappings which do not increase distances, Amer. Math. Monthly, 72, 9 (1965), 1004-1006.

[12] E. Llorens-Fuster, E. Mazcuñán-Navarro and S. Reich, The Ptolemy and Zbăganu constants of normed spaces, Nonlinear Anal., 72, 11 (2010), 3984-3993.

[13] E. MaZcuñán-NAVARRo, Banach spaces properties sufficient for normal structure, J. Math. Anal. Appl., 337, 1 (2008), 197-218.

[14] Y. TAKahashi, Some geometric constants of Banach spaces-a unified approach, in: Banach and Function Spaces II, Proc. International Symposium (ISBFS 2006) held in Kitakyushu (Sept. 14-17, 2006), Edited by Mikio Kato and Lech Maligranda, Yokohama Publ., Yokohama, (2008), 191-220. 
[15] C. YANG AND F. WANG, On a new geometric constant related to the von Neumann-Jordan constant, J. Math. Anal. Appl., 324, 1 (2006), 555-565.

[16] C. YANG AND Y. WANG, Some properties on Jordan-von Neumann type constant of Banach spaces, Acta Math. Sinica Acta Math. Sci. Ser. A., 32A, 1 (2012), 212-221.

[17] C. YANG AND X. YANG, On the James type constant and von Neumann-Jordan constant for a class of Banaś-Fraczieck type spaces, J. Math. Inequal., 10, 2 (2016), 551-558.

[18] C. YANG AND T. WANG, Generalized von Neumann-Jordan constant for the regular octagon spaces, Math. Inequal. Appl., 20, 2 (2017), 483-490.

[19] Z. ZUO AND Y. CUI, A coefficient related to some geometrical properties of Banach space, J. Inequal. Appl., 2009, 1 (2009), 1-14.

[20] Z. Zuo, C. TANG, Schäffer-type constant and uniform normal structure in Banach spaces, Ann. Funct. Anal., 7, 3 (2016), 452-461.

[21] Z. Zuo, C. TANG, X. CHEN AND L. WANG, Jordan-von Neumann type constant and fixed points for multivalued nonexpansive mappings, J. Math. Inequal., 10, 3 (2016), 649-657.

[22] Z. ZUO AND C. TANG, On James and Jordan von-Neumann type constants and the normal structure in Banach spaces, Topol. Methods Nonlinear Anal., 49, 2 (2017), 615-623. 